\title{
Proactive integrated care improves quality of life in patients with COPD
}

\author{
P.B. Koff*, R.H. Jones" ${ }^{\#}$, J.M. Cashman*, N.F. Voelkel` and R.W. Vandivier ${ }^{+}$
}

\begin{abstract}
Self-management strategies improve a variety of health-related outcomes for patients with chronic obstructive pulmonary disease (COPD). These strategies, however, are primarily designed to improve chronic disease management and have not focused on early detection and early treatment of exacerbations. In COPD, the majority of exacerbations go unreported and treatment is frequently delayed, resulting in worsened outcomes. Therefore, a randomised clinical trial was designed to determine whether integration of self-management education with proactive remote disease monitoring would improve health-related outcomes.
\end{abstract}

A total of 40 Global Initiative for Chronic Obstructive Lung Disease stage 3 or 4 COPD patients were randomised to receive proactive integrated care (PIC) or usual care (UC) over a 3-month period. The primary and secondary outcomes were change in quality of life, measured by the St George's Respiratory Questionnaire (SGRQ), and change in healthcare costs.

PIC dramatically improved SGRQ by 10.3 units, compared to 0.6 units in the UC group. Healthcare costs declined in the PIC group by US $\$ 1,401$, compared with an increase of US $\$ 1,709$ in the UC group, but this was not statistically significant. PIC uncovered nine exacerbations, seven of which were unreported.

Therefore, proactive integrated care has the potential to improve outcomes in chronic obstructive pulmonary disease patients through effects of self-management, as well as early detection and treatment of exacerbations.

KEYWORDS: Acute exacerbation of chronic obstructive pulmonary disease, acute management of chronic obstructive pulmonary disease exacerbations, chronic obstructive pulmonary disease, outcome, telemedicine, treatment

hronic obstructive pulmonary disease (COPD) is a debilitating, systemic disease characterised by progressive decline in the ability to perform essential activities of daily living [1]. As lung function worsens, disease exacerbations occur with increasing frequency [1]. For individuals with COPD, exacerbations are the hallmark of a more severe and limiting phase in their illness; a phase punctuated by the need for high-cost medications, increased visits to healthcare providers, emergency departments and hospitals, and an increased risk of death [2, 3]. But, perhaps more importantly, COPD exacerbations herald a steep decline in quality of life [4, 5], in which lives become more defined by boundaries than by possibilities.

On a global level, this phase of COPD also marks the point at which healthcare costs rise sharply. In 2002, direct costs for COPD were US $\$ 18$ billion in the USA and $€ 38.6$ billion in the European Union; of these $\sim 60 \%$ were accounted for by costs related to COPD exacerbations $[1,6]$. Not surprisingly, several studies suggest that the costs associated with COPD rise dramatically as the disease worsens [7-10]. In 2000, Hillman et al. [7] reported that the average cost per patient per year ranged from US $\$ 1,681$ for mild disease to US $\$ 10,812$ in severe disease. Studies from Sweden, Italy and Spain echoed these results, showing up to a 10-fold difference in the cost of mild and severe disease [8-10]. These results make it clear that efforts should be directed toward therapies that more effectively prevent or treat COPD exacerbations. Given that most exacerbations go unreported [11] and that early treatment results in better outcomes [12], treatment models that enhance both the early recognition of exacerbations and the timely delivery of proven therapies should also be targeted.

In patients with COPD, strategies that emphasise patient education and self-management have had mixed success [13]. EfFING et al. [13] analysed controlled trials of self-management education in COPD prior to January 2006 and concluded that "it is likely that self-management education is associated with a reduction in hospital admissions",
AFFILIATIONS

*University of Colorado Hospital Aurora, CO,

\#Dept of Biostatistics, School of Public Health,

${ }^{+}$Dept of Medicine, University of Colorado at Denver

Denver, CO, and

'Dept of Medicine, Virginia Commonwealth University, Richmond, VA, USA.

CORRESPONDENCE

R.W. Vandivier

Dept of Medicine, Division of

Pulmonary Sciences and Critical Care Medicine

University of Colorado at Denver Research Building 2

12700 E. 19th Ave C-272

Aurora

CO 80045

USA

Fax: 13037246042

E-mail: bill.vandivier@ucdenver.edu

Received:

April 242008

Accepted after revision:

December 042008

\section{SUPPORT STATEMENT}

The University of Colorado Hospital supported the study financially and supported the salary of a member of staff for N.F. Voelkel. R.W. Vandivier has received funds for research, salary support and funds for a staff member from the University of Colorado Hospital.

STATEMENT OF INTEREST A statement of interest for this study can be found at www.erj.ersjournals.com/misc/ statements.dtl 
but that there was too much heterogeneity in study design and outcomes to make a firm recommendation. One study included in the review by EFFING et al. [13] demonstrated that a 2-month, intensive education programme increased quality of life and decreased hospitalisations, emergency department visits, and unscheduled outpatient visits in patients with advanced COPD and a history of at least one exacerbation within the previous year [14]. Two follow-up studies to the trial that were not included in the review by EFFING et al. [13] showed that the clinical gains persisted in most instances for up to 2 yrs and that this intervention appeared to be cost-effective $[15,16]$. Therefore, given the knowledge, COPD patients appear to be capable of positively impacting their own outcomes.

Strategies that integrate patient education and self-management with enhanced communication also appear to be effective. CASAS et al. [17] randomised 155 patients, each of whom had recently been hospitalised for a COPD exacerbation, to integrated care $(n=65)$ or usual care $(n=90)$. Integrated care consisted of a comprehensive assessment, an educational programme on self-management, an individually tailored care plan and increased accessibility to healthcare professionals through a web-based call centre. After 12 months, there were fewer hospitalisations and fewer readmissions in the integrated care group, compared with usual care.

Based upon the success of these studies, the current authors designed a pilot, randomised clinical trial to test the hypothesis that a novel, proactive system that integrates daily diseasespecific education, self-management strategies and enhanced communication with remote disease monitoring would result in increased quality of life and decreased healthcare costs in patients with Global Initiative for Chronic Obstructive Lung Disease (GOLD) stage 3 and 4 COPD [1]. The programme was designed

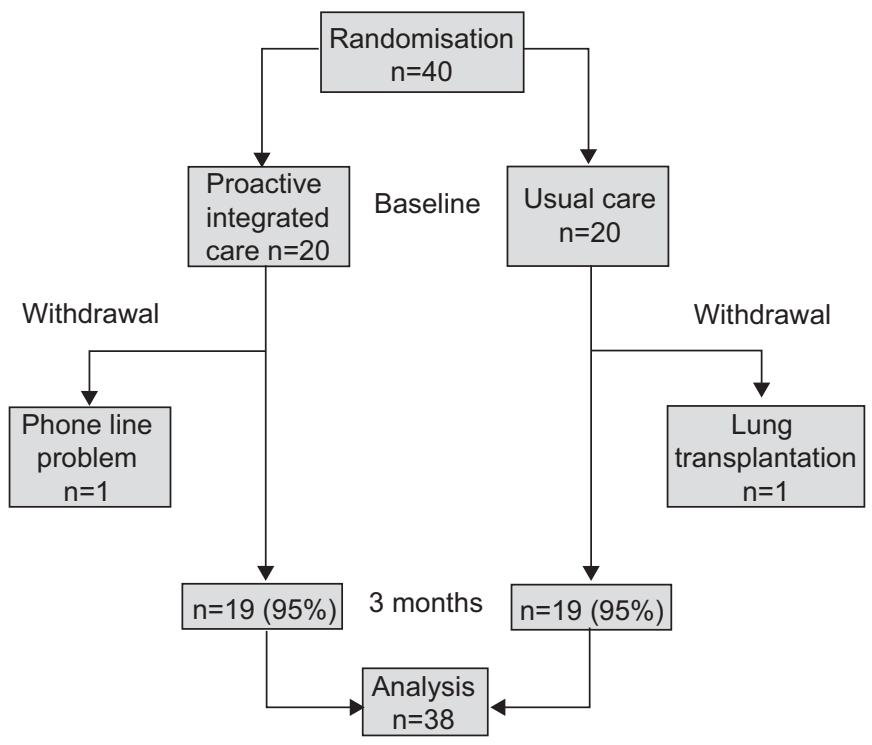

FIGURE 1. Schematic representation of the study flow over a 3-month period. A total of 40 patients were randomised to proactive integrated care or to usual care. Two patients withdrew from the study, one from the proactive integrated care group and one from the usual care group. The final analysis was carried out on 19 patients in each group. to couple successful self-management strategies with an early warning/early intervention system for COPD exacerbations.

\section{MATERIALS AND METHODS \\ Study subjects}

Treatment and control patients were recruited from the COPD clinic and the general pulmonary clinic at the University of Colorado Hospital (Aurora, CO, USA) between November 2004 and June 2005. Inclusion criteria included: 1) GOLD stage 3 or 4 COPD [1]; and 2) a telephone landline. Exclusion criteria included: 1) active treatment for lung cancer; 2) illiteracy; 3) non-English speaking; and 4) inability to complete a 6-min walk test. All participants signed informed consent prior to randomisation, in accordance with the Colorado Multiple Institutional Review Board. Following informed consent, patients randomly selected their group assignment by choosing a blinded envelope that contained a group indicator. Because of the type of intervention, it was not possible to blind the subjects or investigators as to whether they were randomised to the treatment or control arms of the trial. However, personal identifying information was removed for analysis. Figure 1 displays the study flow.

\section{Study design}

The present study was designed as a single-centre, randomised, controlled clinical trial. The main study objective was to determine whether proactive integrated care (PIC) improved quality of life, as measured by a change from baseline in the St George's Respiratory Questionnaire (SGRQ), compared to the usual care (UC) group. Secondary study objectives were to determine whether PIC decreased healthcare costs and whether it identified unreported exacerbations. COPD exacerbations were defined in terms of increasing dyspnoea, sputum production and purulence as originally proposed by ANTHONISEN et al. [18] and later outlined by BURGE and WEDZICHA [19].

Patients in the PIC group received four specific interventions over a 3-month period, including: 1) disease-specific education; 2) teaching of self-management techniques; 3) enhanced communication with study coordinators; and 4) remote home monitoring. Details of these interventions are outlined in the Methods section.

Both PIC and UC groups retained their usual access to healthcare providers. Both groups were evaluated at baseline following a scheduled appointment in the clinic and 3 months later during normal follow-up in the clinic. No contact was made with the UC group between visits.

The study sample size was estimated using data from BOURBEAU et al. [14]. The current authors estimated that 20 patients per group would be necessary to have a $90 \%$ chance of seeing a 2.0 unit improvement in the SGRQ with an SD of 1.9 and an $\alpha$ of 0.05 .

\section{Methods}

PIC group

As outlined in the previous section, PIC consisted of four elements, including: 1) disease-specific education; 2) teaching of self-management techniques; 3) enhanced communication with study coordinators; and 4) remote home monitoring. The 
coordinator administered disease-specific education at enrolment. Thereafter, the Health Buddy ${ }^{\circledR}$ System (HealthHero Network, Palo Alto, CA, USA; acquired in late 2007 by the Bosch Group) dialogue reinforced disease-specific education on a daily basis. This education was based on GOLD guidelines with topics including disease description, medications and their use, nutrition, oxygen therapy and breathing techniques. At enrolment the coordinator taught patients selfmanagement skills (such as use of an oximeter and minispirometer, increased awareness of clinical changes/problems, and appropriate calls to physician offices). Patients were given the cell phone number of the coordinator so that communication would be enhanced through direct contact. Finally, PIC patients were remotely monitored Monday to Friday for changes in symptoms, oxygen saturation, forced expiratory volume in one second (FEV1), and steps in 6-min walk distance (6MWD). PIC patients received a Tuffsat pulse oximeter (GE Healthcare, Chalfont St Giles, UK), a Microlife PF100 FEV1 monitor (iCare Health Monitoring, Golden, CO, USA), an Omron pedometer (Omron Healthcare Inc., Bannockburn, IL, USA), and a technology platform for delivery of education and transmission of the results (Health Buddy® System).

The Health Buddy ${ }^{\circledR}$ System is a small telecommunication device that connects directly to a home telephone; it has been used in the management of several chronic diseases, including COPD, asthma, heart failure and diabetes, and has been used in the management of patients after coronary artery bypass grafting [20-25]. Each weekday morning, patients in the PIC group would participate in a short Health Buddy ${ }_{\circledR}$ System session lasting $\sim 20 \mathrm{~min}$, during which they would receive COPD-specific education, answer symptom-based questions and enter data, including their FEV1, 6MWD as measured by their pedometer, and resting arterial oxygen saturation measured by pulse oximetry $\left(\mathrm{Sp}, \mathrm{O}_{2}\right)$. During these sessions the Health Buddy ${ }_{\circledR}$ System tested patient knowledge, assessed medication compliance and probed for the presence of depression. The Health Buddy ${ }^{\circledR}$ System is a "push-pull" model in that it provides (or pushes) daily education segments and pulls the monitored parameters to the databank by the silent phone call each night. The study coordinator reviewed the results of these sessions the following morning.
Health Buddy ${ }^{\circledR}$ System algorithms segregated patients into three groups, based on their daily responses to symptom-based questions, medication compliance and monitored parameters. Each day the study coordinator viewed patient names that were colour-coded according to their risk, where green indicated stability, yellow indicated caution and red indicated a potential change in health status (table 1). The study coordinator called all patients with red flags and used discretion for patients who had persistent red flags or yellow flags.

The study coordinator, a registered respiratory therapist, interacted with PIC group patients on a number of levels by educating, monitoring and facilitating the delivery of care by primary care physicians. For example, the coordinator instructed patients on the use of home monitoring equipment, interpretation of baseline parameters (i.e. FEV1 and $\mathrm{Sp}_{\mathrm{p}} \mathrm{O}_{2}$ at rest), medication usage, social issues (including smoking and second-hand smoke exposure) and on how a patient should respond to declining health status. The study coordinator monitored patients from Monday to Friday from 09:00 h to 17:00 h, and was available to answer patient questions. Once recognised by a red flag or a patient call, the coordinator would help facilitate the resolution of a clinical problem by calling the patients' primary care physician. In the event of an important nonclinical problem, the coordinator would help the patient make the appropriate contacts.

In PIC patients, the SGRQ was used to assess quality of life at baseline and again at 3 months [26]. Healthcare utilisation was self-reported and compared to actual charges obtained from the University of Colorado Hospital Finance Department during the 3-month study period and the 3-month period preceding the study. Healthcare-related charges included visits to clinics and the emergency room (ER), hospitalisations, radiology services and other diagnostic tests, and blood tests. If known ER or hospital admissions occurred outside the University of Colorado Hospital system, costs were imputed based on Medicare usual and customary standards for hospital general care or intensive care unit admissions.

Equipment satisfaction was assessed in the PIC group at the final interview with a survey in which patients were asked to assign a number from 1 to 10 (1 being strongly dissatisfied and

TABLE 1 Health Buddy System flags

\begin{tabular}{|c|c|c|c|}
\hline Shortness of breath & None & More than usual & Increased \\
\hline Sputum & Usual/white & Yellow & Green/red/brown \\
\hline Fever & $\leqslant 101.5^{\circ} \mathrm{F}$ & & $>101.5^{\circ} \mathrm{F}$ \\
\hline Activity difficulties & None & Some & Yes \\
\hline 6MWD & Walked & No walk $\leqslant 1$ day & No walk $>1$ day \\
\hline $\mathrm{Sp}, \mathrm{O}_{2} \%$ & $>89$ & $88-89$ & $\leqslant 87$ \\
\hline
\end{tabular}

Health Buddy® System is manufactured by HealthHero Network, Palo Alto, CA, USA; acquired in late 2007 by the Bosch Group. FEV1: forced expiratory volume in one second; 6MWD: 6-min walk distance; $\mathrm{Sp}, \mathrm{O}_{2}$ : oxygen saturation as measured by pulse oximetry. 
10 completely satisfied) to each of the individual pieces of equipment used during their 3-month enrolment. Calls made to patients by the study coordinator were tabulated and categorised according to whether they were due to clinical or nonclinical issues and whether they uncovered a COPD exacerbation.

\section{UC group}

Patients in the UC group received none of these interventions and continued on the treatment regimen prescribed by their healthcare provider. Specifically, the coordinator made no effort to change any aspect of the patient's treatment regimen at enrolment. Patients in both the PIC and UC groups answered an enrolment questionnaire, underwent spirometry, 6MWD test, and resting oximetry. The SGRQ was administered to both PIC and UC groups at baseline and after 3 months.

\section{Analysis}

The primary study end-point was the change in the SGRQ over the 3-month study period. This end-point was collected by the coordinator and analysed by R.H. Jones. Secondary end-points were: 1) changes in healthcare costs for the 3-month study period compared with the 3-month period immediately preceding the study; 2) COPD exacerbations; and 3) equipment satisfaction. The baseline characteristics for SGRQ, SGRQ components and healthcare costs were compared using unpaired two-sample t-tests between the PIC and UC control group. The quality of life analysis subtracted the baseline value from the 3-month value for each subject. Unpaired two-sample t-tests based on these differences were carried out between the PIC group and UC group. The exception was healthcare costs, which demonstrated a highly skewed distribution, so the nonparametric Wilcoxon rank sum test was used. SAS PROC MIXED (SAS Insitute Inc., Cary, NC, USA) was used to analyse equipment satisfaction, which involved repeated measures by each subject for each piece of equipment.

\section{RESULTS}

\section{Study subjects}

A total of 40 patients were randomised; 20 to the PIC group and 20 to the UC control group, and one patient withdrew from each group (fig. 1). Baseline characteristics of the groups were similar (table 2), including SGRQ and healthcare costs for the 12 weeks prior to initiation of the study (table 3).

\section{Quality of life}

Over a 3-month period, the SGRQ decreased (improved) by 10.3 units in the PIC group compared to only 0.6 units in the control group $(p=0.018$; table 4$)$. The SGRQ is composed of three components, including symptoms, activity and impact. Over the 3-month period, the SGRQ component scores changed as follows: the symptom score decreased (improved) by 12.8 units in the PIC group compared with only 3.3 units in the control group $(p=0.27)$, the activity score decreased (improved) by 8.8 units in the PIC group compared with only 0.5 units in the control group $(\mathrm{p}=0.16)$; and the impact score decreased (improved) by 6.6 units in the PIC group compared with only 0.6 units in the control group $(p=0.20)$. While the changes in the component scores were not statistically significant, they all moved in the same direction and the combined SGRQ score was significantly different. Therefore,

\section{TABLE 2 Baseline participant characteristics}

\begin{tabular}{|c|c|c|c|}
\hline Characteristics & PIC group & UC group & $p$-value \\
\hline Subjects $n$ & 20 & 20 & \\
\hline Age yrs & $66.6 \pm 9.1$ & $65.0 \pm 8.2$ & 0.52 \\
\hline Females \% & 55 & 50 & 0.75 \\
\hline Ethnicity & & & 0.60 \\
\hline White & 17 & 19 & \\
\hline Black & 2 & 1 & \\
\hline Native American & 1 & 0 & \\
\hline FEV $1 \%$ pred & $33.6 \pm 9.1$ & $31.1 \pm 10.2$ & 0.39 \\
\hline Long-term oxygen therapy \% & 95 & 95 & 1.00 \\
\hline Resting oxygen saturation \% & $92.5 \pm 2.6$ & $93.2 \pm 2.5$ & 0.35 \\
\hline Current smoker \% & 15 & 20 & 0.68 \\
\hline Smoking history pack-yrs & $55.0 \pm 34.9$ & $50.4 \pm 23.6$ & 0.92 \\
\hline Emergency dept visits ${ }^{\#}$ & $0.7 \pm 0.23$ & $0.9 \pm 0.23$ & 0.79 \\
\hline Hospitalisations $^{\#}$ & $0.55 \pm 0.21$ & $0.6 \pm 0.21$ & 0.97 \\
\hline Hospital LOS ${ }^{\#}$ days & $3.2 \pm 7.0$ & $2.8 \pm 5.6$ & 0.82 \\
\hline Influenza vaccination \% & 100 & 85 & 0.23 \\
\hline $\begin{array}{l}\text { Current pulmonary } \\
\text { rehabilitation } \%\end{array}$ & 30 & 20 & 0.72 \\
\hline Prior pulmonary rehabilitation $\%$ & 35 & 40 & 0.74 \\
\hline Lives alone \% & 15 & 30 & 0.45 \\
\hline
\end{tabular}

Data are presented as mean \pm SD, unless otherwise stated. PIC: proactive integrated care; UC: usual care; FEV1: forced expiratory volume in one second; $\%$ pred: \% predicted; LOS: length of stay. ${ }^{\#}$ : in previous year.

these data suggest that the PIC system significantly improves quality of life in severe and very severe COPD patients.

\section{Healthcare costs}

The effect of the PIC system on healthcare costs was then evaluated, which included all healthcare charges generated at the University of Colorado Hospital and, for one treatment patient and one control patient, Medicare reimbursements. Over a 3-month period healthcare costs decreased by US $\$ 1,401$ in the PIC group, compared with an increase of US\$1,709 $(p=0.20)$ in the control group (table 4$)$. While not statistically significant, these data suggest that the PIC system may

\begin{tabular}{|c|c|c|c|}
\hline $\begin{array}{l}\text { TABLE } 3 \text { Baseline St Ge } \\
\text { (SGRQ) charac }\end{array}$ & $\begin{array}{l}\text { rge's Resp } \\
\text { teristics and }\end{array}$ & $\begin{array}{l}\text { atory Questic } \\
\text { healthcare cc }\end{array}$ & $\begin{array}{l}\text { nnaire } \\
\text { sts }\end{array}$ \\
\hline Characteristics & PIC group & UC group & p-value \\
\hline Subjects $n$ & 19 & 19 & \\
\hline SGRQ score & $54.7 \pm 14.9$ & $51.5 \pm 14.3$ & 0.50 \\
\hline \multicolumn{4}{|l|}{ SGRQ components } \\
\hline Symptoms & $56.4 \pm 17.3$ & $51.0 \pm 20.8$ & 0.39 \\
\hline Activity & $77.8 \pm 15.2$ & $76.4 \pm 17.6$ & 0.79 \\
\hline Impact & $38.5 \pm 14.8$ & $35.7 \pm 15.2$ & 0.58 \\
\hline Pre-study healthcare costs US\$ & $7273 \pm 10483$ & $9248 \pm 18897$ & 0.69 \\
\hline
\end{tabular}




\begin{tabular}{|c|c|c|c|}
\hline Measurement & PIC group $(95 \% \mathrm{CI})$ & UC group (95\% Cl) & p-value \\
\hline Subjects $n$ & 19 & 19 & \\
\hline$\Delta$ SGRQ $^{\#}$ score & $-10.3(-17.4--3.1)$ & $-0.6(-6.5-5.3)$ & 0.018 \\
\hline \multicolumn{4}{|l|}{$\Delta$ SGRQ components ${ }^{\#}$} \\
\hline Symptoms & $-12.8(-24.4--1.1)$ & $-3.3(-14.0-7.4)$ & 0.27 \\
\hline Activity & $-8.8(-18.8-1.1)$ & $-0.5(-8.9-7.9)$ & 0.16 \\
\hline Impact & $-6.6(-15.3-2.2)$ & $-0.6(-7.2-6.0)$ & 0.20 \\
\hline$\Delta$ healthcare costs ${ }^{\top}$ US\$ & $-1401(-6566-3764)$ & 1709 (-4349-7768) & 0.21 \\
\hline
\end{tabular}

PIC: proactive integrated care; Cl: confidence interval; UC: usual care; SGRQ: St George's Respiratory Questionnaire. "\#: difference in score at 0 and 3 months; $\because$ difference between costs during study period and during prestudy period

decrease healthcare costs, but this would need to be established in a larger trial.

\section{COPD exacerbations}

The Health Buddy® System algorithm identified all nine COPD exacerbations in the PIC group patients and, in each case, resulted in the activation of a red flag (table 5). Resting hypoxaemia was the most frequent red flag activated (table 6). Based on these red flags, the Health Buddy® System remotely advised all nine patients to immediately contact their coordinator; interestingly though, only two patients made this call and the rest were contacted by the coordinator the next day (table 5). Of the nine exacerbations identified in the PIC group during the study period, one resulted in a visit to the ER and a hospitalisation (table 5), while eight were successfully treated on an outpatient basis. In contrast, there were more exacerbationrelated ER visits and hospitalisations in the UC group during the study period, compared with the PIC group (table 5).

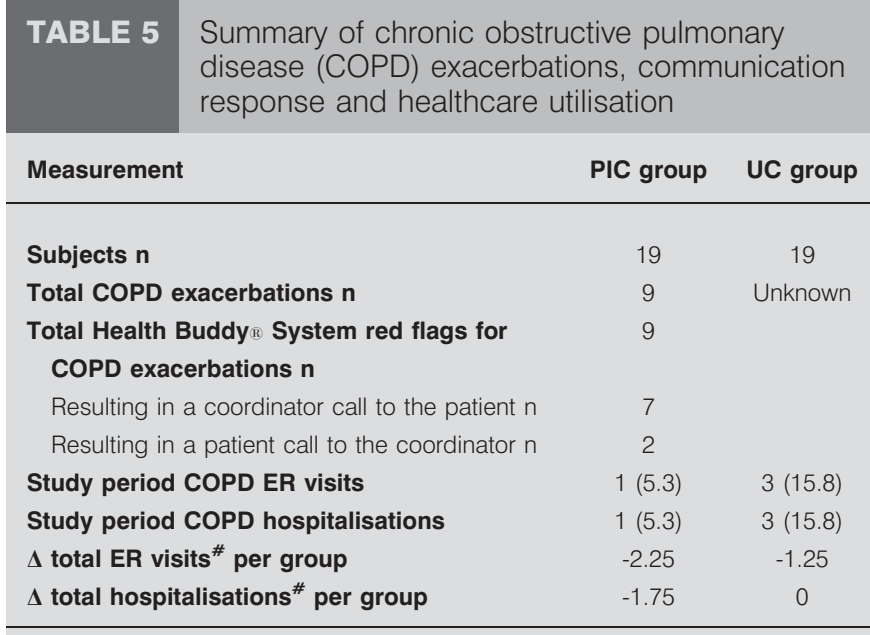

Data are presented as $n(\%)$, unless otherwise stated. PIC: proactive integrated care; UC: usual care; ER: emergency room. ${ }^{*}$ : difference between during study period and during pre-study period. Health Buddy $y^{\circledR}$ System is manufactured by HealthHero Network, Palo Alto, CA, USA; acquired in late 2007 by the Bosch Group.

\begin{tabular}{l|l}
\hline TABLE 6 & $\begin{array}{l}\text { Health Buddy } \\
\text { chronic obstructive pulmonary disease (COPD) } \\
\text { exacerbations }\end{array}$ \\
\hline Red flag & $\begin{array}{c}\text { Red flags activated for COPD } \\
\text { exacerbations }\end{array}$ \\
\hline Sp, $\mathbf{O}_{\mathbf{2}}$ & $5(56)$ \\
Shortness of breath & $2(22)$ \\
$\mathbf{F E V} \mathbf{1}$ & $1(11)$ \\
Cough & $1(11)$
\end{tabular}

Data are presented as $\mathrm{n}$ (\% of total). $\mathrm{Sp}, \mathrm{O}_{2}$ : arterial oxygen saturation measured by pulse oximetry; FEV1: forced expiratory volume in one second. Health Buddy System is manufactured by HealthHero Network, Palo Alto, CA, USA acquired in late 2007 by the Bosch Group.

When COPD-related ER visits and hospitalisations during the study period were compared to those reported during the pre-study period, it was found that PIC was associated with a decrease in both, compared with the UC group (table 5). Because of the small numbers, data in table 5 are descriptive only and have not been analysed statistically. These results suggest that the PIC system can proactively identify COPD exacerbations, leading to earlier treatment, fewer ER visits and fewer hospitalisations.

\section{Equipment satisfaction}

In addition to the primary and secondary end-points noted above, patient satisfaction with the equipment used at home was assessed. During their final interview, patients were asked to assign a number from 1 to 10 (1 being strongly dissatisfied and 10 completely satisfied) to each of the individual pieces of equipment used during their 12-week enrolment. Results are shown in table 7, and demonstrate that there was high satisfaction for all of the equipment, except for the pedometer, which did not accurately count steps for patients whose gait was soft.

\section{Communication}

During the 3-month study period, a total of 190 calls were made to the 20 subjects in the PIC group (table 8), which is an average of 3.2 calls per patient per month. These calls were

\section{TABLE 7 Equipment satisfaction}

\begin{tabular}{lcc} 
Equipment & Respondents $\mathbf{~}$ & Score $^{\#} \mathbf{( 9 5 \% ~ C I )}$ \\
\hline Pulse oximeter & 19 & $9.6(8.7-10.0)$ \\
Health Buddy ${ }_{\mathbb{R}}$ System & 19 & $9.1(8.1-10.0)$ \\
Spirometer & 17 & $8.5(7.5-9.5)$ \\
Pedometer & 14 & $4.5(3.4-5.5)^{\bullet}$ \\
\hline
\end{tabular}

Cl: confidence interval. * : scored 1-10, with 1 being completely dissatisfied and 10 completely satisfied; $\because$ : $p<0.0001$ for pedometer compared with all other groups. Health Buddy ${ }_{\circledR}$ System is manufactured by HealthHero Network, Palo Alto, CA, USA; acquired in late 2007 by the Bosch Group. 


\begin{tabular}{lcc}
\hline TABLE 8 Communication & Calls $\mathbf{n}$ & $\begin{array}{c}\text { Calls requiring a } \\
\text { physician response }\end{array}$ \\
\hline Call type & $190(100)$ & $29(15.3)$ \\
\hline Total & $83(43.7)$ & $27(14.2)$ \\
Clinical & $71(37.4)$ & $21(11.0)$ \\
Respiratory & $12(6.3)$ & $6(3.2)$ \\
Nonrespiratory & $107(56.3)$ & $2(1.1)$ \\
Nonclinical & $30(15.8)$ & $0(0)$ \\
Equipment issues & $31(16.3)$ & $2(1.1)$ \\
Integrated services & $30(15.7)$ & $0(0)$ \\
Missed sessions & $16(2.7)$ & $0(0)$ \\
Miscellaneous & & \\
\hline & &
\end{tabular}

fairly equally split between clinical (44\%) and nonclinical (56\%) issues. Of the calls, 37\% were for clinical respiratory problems while only $6 \%$ of calls were for clinical nonrespiratory issues, such as depression. The reasons for nonclinical calls were equally divided between equipment questions or problems, missed sessions and the need for integrated services, which included problems with health insurance, maintaining utilities or affording medications. Overall, only $15 \%$ of calls required the input of a physician, while the study coordinator handled the remaining calls independently.

\section{DISCUSSION}

The present randomised clinical trial examined the ability of a COPD-specific PIC system to positively impact quality of life and healthcare costs when coupled with a proactive early warning/early intervention system. The results demonstrate that this novel model of PIC markedly improves quality of life over the intervention period, and suggest that healthcare costs may be reduced, perhaps through increased recognition and early treatment of COPD exacerbations.

PIC markedly improved quality of life to a degree that was unexpected (i.e. 10.3 units), in that it was highly significant [26-28] and much greater than changes seen in similar selfmanagement trials. For example, BOURBEAU et al. [14] and colleagues measured the effect of a COPD-specific selfmanagement intervention on a patient population with a similar degree of illness severity. At a comparable 4-month time-point, self-management improved SGRQ by 6.4 units compared with 2.3 units in the UC group. In a less severely ill patient population, MONNINKHOF et al. [29] found that selfmanagement had no effect on SGRQ at 6 months, compared to the UC group. Similarly, in a nonrandomised study, TRAPPENBURG et al. [25] found that an unmodified Health Buddy® System dialogue had no effect on healthcare-related quality of life, despite showing that the Health Buddy® System decreased rates of hospital admissions and exacerbations. The only other clinical trial examining the effect of an integrated care programme on health-related outcomes was performed by CASAS et al. [17], in which quality of life was found to improve at 6 and 12 months (personal communication; C. Hernandez and J. Roca, Hospital Clínic, IDIBAPS, Universitat de Barcelona, Barcelona, Spain). Therefore, a PIC programme that stresses patient education, self-management, increased communication and early warning/early intervention improves health-related quality of life to a level that has been described as "very effective" for COPD [28].

The PIC programme appeared to have a positive effect on healthcare costs. While these changes were not statistically significant, they were intriguing because of their magnitude and differential direction over a relatively short period of time. The analysis was primarily based on all healthcare costs that were generated at the University of Colorado Hospital, and included all healthcare-related charges, such as visits to outpatient clinics and the ER, hospitalisations, blood and other tests, and radiology services. The current authors recognise, however, that the analysis was incomplete in that it did not all include healthcare-related services outside of the University of Colorado Hospital.

The positive impact of the PIC programme on quality of life and healthcare costs was probably derived from a combination of factors including disease-specific education, increased ability to self-manage, heightened contact with healthcare providers, and remote monitoring resulting in early warning and early treatment. Unfortunately, the relative importance of these factors cannot be teased apart. As previously discussed, the high number of Health Buddy® System-triggered calls for COPD exacerbations suggest that early warning/early intervention may have had a positive impact. Only two patients called the study coordinator because of deterioration in their health status. Therefore, patients did not recognise their clinical deterioration, did not recognise its importance or, paradoxically, were over-reliant on the remote monitoring. This question cannot be answered definitively with the available data. However, based on the fact that more than two thirds of exacerbations go unreported [11] and that COPD patients are known to poorly perceive dyspnoea [30], the current authors speculate that poor perception of both symptoms and risk are to blame.

The present authors recognise that the study is limited in several ways. 1) A relatively small number of patients were enrolled in the study, increasing the chance of a type-I error. 2) Patients were enrolled from a university hospital tertiary care setting. While this is certainly a limitation that prevents generalisation of the results, it is also a setting in which one would expect care to have already been maximised; optimal care could have been predicted to limit the impact of the programme. 3) The period of the intervention was short and in some cases did not overlap the influenza season. 4) The effect of the PIC programme on quality of life was only measured during the intervention period and not for periods after the interventions had stopped. However, data from GADOURY et al. [16] suggest that the effects of self-management programmes can last for up to 2 yrs. 5) The study was not designed or powered to determine effects on healthcare utilisation and costs over an extended period. Therefore, the healthcare cost analysis is not a rigorous assessment and a cost-effectiveness analysis was not explicitly performed. A more definitive assessment of the healthcare cost benefits versus the programme costs should await a larger, adequately powered clinical trial. 6) Finally, there is likely to have been some degree of a placebo effect in the PIC 
group because of the remote monitoring and more frequent contact with the coordinator.

In summary, the present study tested the efficacy of a novel proactive integrated care programme on health-related outcomes in chronic obstructive pulmonary disease patients. The data show that this approach dramatically improves quality of life, and suggest the possibility that it may decrease healthcare costs by initiating early treatment of chronic obstructive pulmonary disease exacerbations.

\section{ACKNOWLEDGEMENTS}

The authors would like to thank the Barcelona CHRONIC team at the Hospital Clínic of the University of Barcelona for their leadership in advancing the concept of an integrative care approach. The authors also thank P. Jones (St George's, University of London, London, UK) for his gracious consent to use the St George's Respiratory Questionnaire.

\section{REFERENCES}

1 Rabe KF, Hurd S, Anzueto A, et al. Global strategy for the diagnosis, management, and prevention of chronic obstructive pulmonary disease: GOLD executive summary. Am J Respir Crit Care Med 2007; 176: 532-555.

2 Seneff MG, Wagner DP, Wagner RP, Zimmerman JE, Knaus WA. Hospital and 1-year survival of patients admitted to intensive care units with acute exacerbation of chronic obstructive pulmonary disease. JAMA 1995; 274: 1852-1857.

3 McGhan R, Radcliff T, Fish R, Sutherland ER, Welsh C, Make B. Predictors of rehospitalization and death after a severe exacerbation of COPD. Chest 2007; 132: 1748-1755.

4 Seemungal TA, Donaldson GC, Paul EA, Bestall JC, Jeffries DJ, Wedzicha JA. Effect of exacerbation on quality of life in patients with chronic obstructive pulmonary disease. Am J Respir Crit Care Med 1998; 157: 1418-1422.

5 Spencer S, Calverley PM, Burge PS, Jones PW. Impact of preventing exacerbations on deterioration of health status in COPD. Eur Respir J 2004; 23: 698-702.

6 Chapman KR, Mannino DM, Soriano JB, et al. Epidemiology and costs of chronic obstructive pulmonary disease. Eur Respir J 2006; 27: 188-207.

7 Hilleman DE, Dewan N, Malesker M, Friedman M. Pharmacoeconomic evaluation of COPD. Chest 2000; 118: 1278-1285.

8 Jansson SA, Andersson F, Borg S, Ericsson A, Jonsson E, Lundback B. Costs of COPD in Sweden according to disease severity. Chest 2002; 122: 1994-2002.

9 Dal Negro R, Berto P, Tognella S, Quareni L, Global Outcomes in Lung Disease Study Group, Cost-of-illness of lung disease in the TriVeneto Region, Italy: the GOLD Study. Monaldi Arch Chest Dis 2002; 57: 3-9.

10 Miravitlles M, Murio C, Guerrero T, Gisbert R. Costs of chronic bronchitis and COPD: a 1-year follow-up study. Chest 2003; 123: 784-791.

11 Langsetmo L, Platt RW, Ernst P, Bourbeau J. Underreporting exacerbation of chronic obstructive pulmonary disease in a longitudinal cohort. Am J Respir Crit Care Med 2008; 177: 396-401.
12 Wilkinson TM, Donaldson GC, Hurst JR, Seemungal TA Wedzicha JA. Early therapy improves outcomes of exacerbations of chronic obstructive pulmonary disease. Am J Respir Crit Care Med 2004; 169: 1298-1303.

13 Effing T, Monninkhof EM, van der Valk PD, et al. Selfmanagement education for patients with chronic obstructive pulmonary disease. Cochrane Database Syst Rev 2007; 4: CD002990.

14 Bourbeau J, Julien M, Maltais F, et al. Reduction of hospital utilization in patients with chronic obstructive pulmonary disease: a disease-specific self-management intervention. Arch Intern Med 2003; 163: 585-591.

15 Bourbeau J, Collet JP, Schwartzman K, Ducruet T, Nault D, Bradley C. Economic benefits of self-management education in COPD. Chest 2006; 130: 1704-1711.

16 Gadoury MA, Schwartzman K, Rouleau M, et al. Selfmanagement reduces both short- and long-term hospitalisation in COPD. Eur Respir J 2005; 26: 853-857.

17 Casas A, Troosters T, Garcia-Aymerich J, et al. Integrated care prevents hospitalisations for exacerbations in COPD patients. Eur Respir J 2006; 28: 123-130.

18 Anthonisen NR, Manfreda J, Warren CP, Hershfield ES, Harding GK, Nelson NA. Antibiotic therapy in exacerbations of chronic obstructive pulmonary disease. Ann Intern Med 1987; 106: 196-204.

19 Burge S, Wedzicha JA. COPD exacerbations: definitions and classifications. Eur Respir J 2003; 21: Suppl. 41, 46s-53s.

20 Barnason S, Zimmerman L, Nieveen J, Hertzog M. Impact of a telehealth intervention to augment home health care on functional and recovery outcomes of elderly patients undergoing coronary artery bypass grafting. Heart Lung 2006; 35: 225-233.

21 Dang S, Ma F, Nedd N, Aguilar EJ, Roos BA. Differential resource utilization benefits with Internet-based care coordination in elderly veterans with chronic diseases associated with high resource utilization. Telemed J E Health 2006; 12: 14-23.

22 Guendelman S, Meade K, Benson M, Chen YQ, Samuels S. Improving asthma outcomes and self-management behaviors of inner-city children: a randomized trial of the Health Buddy interactive device and an asthma diary. Arch Pediatr Adolesc Med 2002; 156: 114-120.

23 LaFramboise LM, Todero CM, Zimmerman L, Agrawal S. Comparison of Health Buddy with traditional approaches to heart failure management. Fam Community Health 2003; 26: 275-288.

24 Miller C, Zimmerman L, Barnason S, Nieveen J. Impact of an early recovery management intervention on functioning in postoperative coronary artery bypass patients with diabetes. Heart Lung 2007; 36: 418-430.

25 Trappenburg JC, Niesink A, de Weert-van Oene GH, et al. Effects of telemonitoring in patients with chronic obstructive pulmonary disease. Telemed J E Health 2008; 14: 138-146.

26 Jones PW, Quirk FH, Baveystock CM, Littlejohns P. A selfcomplete measure of health status for chronic airflow limitation. The St. George's Respiratory Questionnaire. Am Rev Respir Dis 1992; 145: 1321-1327.

27 Jones PW, Bosh TK. Quality of life changes in COPD patients treated with salmeterol. Am J Respir Crit Care Med 1997; 155: 1283-1289. 
28 Jones PW. Interpreting thresholds for a clinically significant change in health status in asthma and COPD. Eur Respir J 2002; 19: 398-404.

29 Monninkhof E, van der Valk P, Schermer T, van der Palen J, van Herwaarden C, Zielhuis G. Economic evaluation of a comprehensive self-management programme in patients with moderate to severe chronic obstructive pulmonary disease. Chron Respir Dis 2004; 1: 7-16.

30 Ekici A, Yilmaz S, Ekici M, et al. Perception of bronchoconstriction in obstructive pulmonary diseases (disease-specific dyspnoea). Clin Sci (Lond) 2003; 105: 181-185. 